This is a self-archived version of an original article. This version may differ from the original in pagination and typographic details.

Author(s): Mauno, Saija; Kubicek, Bettina; Minkkinen, Jaana; Korunka, Christian

Title: Antecedents of intensified job demands : evidence from Austria

Year: 2019

Version: Accepted version (Final draft)

Copyright: (c) 2019, Emerald Publishing Limited

Rights: In Copyright

Rights url: http://rightsstatements.org/page//nC/1.0/?language=en

Please cite the original version:

Mauno, S., Kubicek, B., Minkkinen, J., \& Korunka, C. (2019). Antecedents of intensified job demands : evidence from Austria. Employee Relations, 41(4), 694-707.

https://doi.org/10.1108/ER-04-2018-0094 
This is the post print version of the article, which has been published in Employee Relations 2019, 41 ( 4 ), $694-707$. https://doi.org/10.1108/ER-04-2018-0094

\section{Antecedents of intensified job demands: evidence from Austria}

Mauno, S.; Kubicek, B.; Minkkinen, J.; Korunka, C

\section{Abstract \\ Research paper}

Purpose: In order to understand the driving forces behind intensified job demands (IJDs), this study examined demographic factors, structural work-related factors, personal and job resources as antecedents of IJDs.

Design/Methodology/Approach: The study is based on cross-sectional (N=4963) and longitudinal ( $\mathrm{N}=2055)$ quantitative datasets of Austrian employees. Datasets were analyzed via regression analyses.

Findings: The results showed that IJDs, as assessed through five sub-dimensions; (1) work intensification, (2) intensified job-related and (3) career-related planning and decision-making demands and (4) intensified demands for skills, and (5) for knowledge-related learning, remained fairly stable over time. The most consistent antecedents of IJDs were personal initiative and ICT use at work. Job resources, e.g., variety of tasks and lacking support from supervisor, related to four sub-dimensions of IJDs.

Research implications: The findings suggest that personal (being initiative) and job resources (task variety) may have negative effects as they associated with IJDs. Moreover, supervisors’ support is crucial to counteract IJDs.

Practical implications: Employers should recognize that certain personal (e.g., personal initiative) and job-related resources (e.g., lacking supervisory support) might implicate higher IJDs, which, in turn, may cause more job strain as IJDs can be conceived as job stressors. Originality/value: IJDs have received very little research attention because they are new job demands which, however, can be expected to increase in future due to faster technological acceleration in working life. The study has methodological value as longitudinal design was applied. 


\section{Introduction}

\subsection{Background and aim}

Digitalization, globalization, and 24/7 society are all hallmarks of modern society (Green, 2004; Rosa, 2003). These phenomena have caused dramatic changes in working life, which has become more intense and effort-demanding. One implication of such intensification is increased cognitive demands (stressors) at work. Indeed, many jobs may nowadays be more stressful cognitively and mentally due to high organizational profit-making demands and to an increase in service and knowledge work as opposed to industrial work, resulting in an erosion of manual less cognitive work. ICT and increasingly also artificial intelligence are utilized extensively in work, signifying that work is not only more cognitively demanding, but also loaded with expectations for increased effectiveness as ICT speeds up knowledge transmission, work processes, and interconnectedness (Chesley, 2014; Green, 2004; Kubicek et al., 2014, 2015). Altogether, these changes are likely to intensify work, implying extended cognitive job demands (Chesley, 2014; Kubicek et al., 2014, 2015). In this study, we call this phenomenon intensified job demands, i.e., IJDs (defined in Chapter 1.2., Kubicek et al., 2015).

There is already evidence showing that employees perceive IJDs as job stressors as they have been found to be detrimental to employees' health and well-being, e.g., in terms of job burnout, job dissatisfaction, and psychosomatic symptoms (Chesley, 2014; Franke, 2015; Korunka et al., 2015; Kubicek et al., 2015). Hence, from the viewpoint of occupational health, IJDs are extremely relevant. However, less attention has so far been paid to the question of what precedes IJDs. Here we propose that answering this question would have valuable practical implications for organizations and employers by identifying which factors require interventions in order to curb IJDs. Even though theoretical reasoning on the causes of IJDs has already been presented (Green, 2004; Rosa, 2003, see Chapter 1.2.), empirical research on their predictors is scarce and predominantly cross-sectional. Accordingly, the present study examines the 
antecedents of IJDs, which will be sought from (1) demographic factors, (2) structural workrelated factors, (3) personal resources, and (4) from job resources. Empirically our study is based on a large diverse sample of Austrian employees $(\mathrm{N}=4963)$, which is also analyzed longitudinally ( $\mathrm{N}=2055$, time-lag 16 months). To the best of our knowledge, this is the first longitudinal study on the predictors of IJDs, also shedding new light on their different aspects and their possibly different predictors.

\subsection{Defining multi-dimensional IJDs}

The sociological foundations of IJDs rely on the theory of social acceleration (Rosa, 2003), proposing that acceleration is a constitutive part of modern social life. Rosa defines social acceleration as a multi-faceted phenomenon consisting of three different processes which propel each other in a circle. Technological acceleration, defined by Rosa as the acceleration of communication, transportation or production processes is evident, e.g., in the ever-increasing pace of computer advances. Technological acceleration, in turn, triggers the acceleration of social change referring to the ever-faster transformation of social structures, relationship patterns and lifestyles in modern Western societies (Rosa, 2003). Moreover, the increasing speed of technological innovation and societal change accelerate the pace of life. People feel impelled to squeeze ever more actions into a day to exhaust as many options as possible. This contributes to feelings of time pressure and the perception that one is unable to keep up. The perceived time scarcity creates a desire to save time and a need for further technological innovation, fueling the acceleration circle.

Rosa's theory helps understand changes in current work. Recently, Kubicek et al. (2015) used this theory to develop the concept of IJDs. They propose that social acceleration contributes to an intensification of job demands. Particularly, workload, planning and decisionmaking, and learning demands have intensified according to Kubicek et al. (2015). Work intensification (WI), which may be directly linked to Rosa’s (2003) notion of an accelerating 
pace of life, refers to the fact that the amount of effort employees need to invest during the working day has increased. Kubicek et al. (2015) propose that WI is characterized by the need to work ever faster, perform different tasks simultaneously, or reduce idle time.

Intensified job-related and career-related planning and decision-making demands refer to the fact that employees are nowadays confronted with the demand to take more job and career-related decisions than formerly (Kubicek et al., 2015). On the job level, employees are increasingly expected to plan and structure their working day autonomously (Wood, 2011), to determine how to handle tasks and also to set and control goals. Although this way of organizing work benefits employers and workers as it increases workers' effectiveness and improves quality of life (Gajendran and Harrison, 2007), it simultaneously intensifies job-related planning and decision-making demands (IJPD) (Allvin et al., 2011). On the career level, employees are increasingly required to become strategic actors who continuously confirm and prove their value for their employers and enhance their future employability outside the organization (Pongratz and Voß, 2003). Pongratz and Voß (2003) argue that self-directedness and individual responsibility have become important demands for employees. Following this notion of career development as a demand, Kubicek et al. (2015) conceptualized intensified career-related planning and decision-making demands (ICPD) as the increasing requirement to autonomously plan and pursue one's career inside and outside of the organization.

Finally, intensified learning demands result from the acceleration of technological and social change. Employees are required to constantly update their knowledge and adjust their skills to keep up with technological and societal changes (Korunka et al., 2015). Thus, workrelated learning demands entail both intensified knowledge-related (IKLD) and intensified skillrelated learning (ISLD) (Kubicek et al., 2015). In sum, the model by Kubicek et al. (2015) includes altogether five different aspects of IJDs: WI, IJPD, ICPD, IKLD, and ISLD. 


\subsection{Antecedents of the IJDs and related earlier findings}

\subsubsection{Demographic factors: gender, age, education}

Demographic predictors in our study include gender, age, and education, all of which have been studied in job stress research, but less so in relation to IJDs. There is so far very little research on gender differences in IJDs. However, a recent study by Paškvan and Kubicek (2017) showed that gender associated differently with WI (a key dimension of IJDs) in different countries, e.g., in Germany men and in America women reported higher WI. Overall, the findings on gender differences in the perceptions of job stressors are fairly inconsistent (Gyllensten and Palmer, 2005; Jick and Mitz, 1985).

There is some preliminary evidence suggesting that the perceptions of IJDs may differ by age, but also these findings are so far inconsistent and very scant as they have concerned only one sub-dimension of IJDs, that is, WI. Paškvan and Kubicek (2017) reported that older employees perceived WI more frequently in Germany, whereas in America younger employees scored higher on WI. As IJDs describe mostly cognitive job stressors, we can also refer to research which has examined age in relation to other types of cognitive job demands. Taken together these studies suggest that aging at work may co-occur with some cognitive impairments, but it may also imply some cognitive gains (e.g., in terms of work experience), compensating the effects of cognitive (skills) impairments (Fisher et al., 2014; Martin and Zimbrich, 2005).

Finally, we reasoned that a level of education may also predict IJDs, and this factor is also examined in our study. As was the case for gender and age, prior research is inconsistent regarding the relationship between education level and IJDs. Paškvan and Kubicek (2017) found that in Germany less educated, whereas in America more highly educated workers reported higher WI. Again, it is important to note that the linkages between education and other dimensions of IJDs have not yet been studied, so these earlier findings should be interpreted with caution. On the one hand, higher education, as a component of higher socioeconomic status, may 
constitute a remarkable resource for an employee (Pinquart and Sorensen, 2000). Thus a welleducated individual may be competent, skilled and cognitively prepared to meet new, mostly cognitive, job demands, implying that highly educated employees may experience less IJDs than do less educated employees. On the other hand, highly educated individuals may be more negatively affected by IJDs as their work is typically ICT-based, which is causing technological acceleration and related work intensification (Chesley, 2014; Rosa, 2003).

\subsubsection{Structural work-related factors: working hours, ICT use, managerial position, income,} sector

In our study, weekly working hours, ICT use at work, managerial position, monthly income, and sector (private vs. public) are examined as structural work-related predictors of IJDs. Longer weekly working hours have repeatedly been found to predict higher job stress (Bannai and Tamakoshi, 2014; Lee et al., 2017). Thus we can assume that longer working hours imply higher IJDs. The causes of IJDs are in requirements for more intensified and effortdemanding work behaviors, very likely meaning that employees have to work more and longer hours (Green, 2004; Kubicek et al., 2015; Paškvan and Kubicek, 2017).

The second structural work-related antecedent, ICT use at work, has clear underpinnings in social acceleration theory (Rosa, 2003), proposing that ICT is one major cause of technological and related social acceleration and work intensification (Chesley, 2014; Green, 2004; Kubicek et al., 2014, 2015). Moreover, in upcoming digitalization and robotization the role of ICT will be even greater, probably causing more job stress for employees. As a result, it can be proposed that frequent ICT use at work associates with higher IJDs.

Managerial position is the third structural work-related antecedent factor for IJDs examined in our study. Managers are likely to experience high job stress because their work is demanding, but there are also findings which show that managerial work includes compensatory resources (e.g., support, control), assisting managers to cope with high job demands (Haus et al., 
2016; Waszkowska et al., 2017). On the one hand, being in a managerial position may come with more capital and resources (e.g., cognitive abilities, support), which may help managers to cope with IJDs. On the other hand, managers may also be more severely hit by IJDs as their work is already demanding and IJDs constitute additional stressors for them (Hassard et al., 2011).

The fourth factor that we study as a work-related antecedent of IJDs is monthly income. It is well acknowledged that income is associated with an employee's education and job status, forming the components of socioeconomic status (SES). Higher SES (high education, high income, and high job position) constitutes a notable personal resource. Studies have also shown that higher SES is linked to better working conditions (e.g., lower job demands; Warren et al., 2004). The specific relationship between income and IJDs has not been studied before. However, it may be that higher income employees experience less IJDs as income constitutes a significant personal resource, but they may also perceive higher IJDs as higher income typically means higher job status with cognitively more demanding jobs alongside greater job stress.

The final structural work-related factor is employment sector (private vs. public). Although an intensification of job demands is observable in many organizations and industries (Kubicek et al., 2015), employees in the private and public sectors might experience different kinds of IJDs. WI could be more pronounced in the public sector (Felstead et al., 2013) due to the implementation of new public management (Omari and Paull, 2015). According to Felstead et al. (2013), between 1992 and 2012, the percentage of jobs requiring hard work rose much more markedly in the public than in the private sector. On the other hand, public employees have historically had lower job mobility and higher job security than private sector workers, and this difference has persisted in recent years (Munnell and Fraenkel, 2013). Job-related as well as career-related decision-making demands and learning demands may thus have increased less in the public sector than in the private sector in recent years. Consequently, it is possible that being employed in the public sector is related to higher WI, whereas being employed in the private 
sector could be associated with higher intensified learning demands (IKLD, ISLD) and intensified planning and decision-making demands (IJPD, ICPD). We will also examine this possible scale-based variation, i.e., public vs. private sector predicts different dimensions of IJDs.

\subsubsection{Personal resources: personal initiative and optimism}

Personal resources cover various factors, e.g., personality characteristics, dispositions, coping skills, and intelligence, which are important in coping with life demands and in staying healthy in life adversities, including stressful working conditions (Furnham, 2008). This reasoning is also consistent with a theory introduced by Bolger and Zuckerman (1995) on the role of personal resources in a stress process; one of their key models proposes that personal resources predict how stressful a person experiences his/her environment, including work, justifying the proposition of personal resources as antecedents of work demands, including IJDs. Among the various personal resources, we focus on two dispositional personal resources as antecedents of IJDs, namely personal initiative and optimism.

Personal initiative is defined as a behavioral tendency resulting in an individual taking an active and self-starting approach to work goals and tasks (i.e., a proactive action tendency at work) and being persistent in overcoming barriers and setbacks that occur at work (Fay and Frese, 2001; Frese et al., 1996, 1997). Thus personal initiative is a direct opposite to a passive orientation/behavioral tendency. Personal initiative is a significant personal resource and associated with many positive work-related outcomes, e.g., performance at work and profitmaking (Fay and Frese, 2001; Frese et al., 1996, 1997), implying that those who are high in personal initiative may also appraise their (work) environment more positively and less stressful. Consequently, we can assume that higher personal initiative implies also lower IJDs (if high IJDs are characterizing highly stressful environment). 
Optimism is a relatively stable personality trait/ disposition characterized by general positive expectations affecting a person’s motivated action, and when encountering obstacles or harm, those who are optimistic typically anticipate positive outcomes (Carver et al., 2010; Scheier and Carver, 1992). Meta-analyses indicate that dispositional optimism is a crucial personal resource associated with many positive consequences, e.g., better psychological health (e.g., Anderson, 1996). Optimistic individuals may also perceive fewer negative stressors in their (work) environment (Carver et al., 2010). For these reasons, it is highly likely that greater optimism associates with lower IJDs in this study.

\subsubsection{Job resources: job control and supervisor support}

Since Karasek launched and later elaborated the job demand-control model, two influential job resources have characterized job stress research, namely job control and social support at work (Karasek, 1979; Karasek and Theorell, 1990). Job control refers to an employee's control over decisions concerning how to perform work tasks, when and where to perform them, and control over decision-making more broadly in the organization, while social support at work refers to emotional support received from co-workers and/or supervisors (Karasek and Theorell, 1990). Here we focus on job control (schedule control, task variety) and supervisory social support as job-related resources in predicting IJDs. Both job control and social support are crucial job resources related to various positive outcomes, for example, better psychological and physical health, as has been documented in reviews and meta-analysis based on Karasek’s model (van der Doef and Maes, 1999; Häusser et al., 2010). Moreover, job resources, including control and support, may not only protect against job strain, i.e., resulting in better well-being and health under high job stress, but may also affect how stressful and demanding employees perceive their working environment, as has been presented in the JD-R model (Demerouti et al., 2001). Based on this evidence, job control and supervisory social 
support should render the working environment less stressful for employees, and thus these two job-related resources should be associated with lower IJDs.

\subsection{Data and Methods}

\subsection{Participants and procedure}

Several organizations in the Austrian public and private sectors took part in this survey-based study. After receiving permission from the organizations' managements, employees were asked to participate in an online survey. Participation was voluntary and anonymity was guaranteed. In return for their participation, the organizations’ managements received feedback about their employees’ summarized ratings of working conditions, IJDs, and well-being. In the first round of data collection, 4,963 employees participated in the study. Of the participants, 56\% were male, 53\% worked in the public sector, and $19 \%$ had a managerial position. Participants were on average 40.45 years of age (SD=9.61), worked 41.10 hours per week (including overtime, $\mathrm{SD}=8.36$ ) and had been 12.86 years with their current employer $(\mathrm{SD}=10.40)$.

After a time lag of approximately 16 months, the organizations were contacted again to pursue the second round of data collection. Ten out of the thirteen participating organizations took part in this second wave of data collection. Again, feedback was provided to the managements of the participating organizations concerning summarized ratings of working conditions, IJDs, and well-being. In total, 4,247 employees responded to the survey. Using a personal code, 2,055 participants, i.e., 41\% of the respondents at Time 1 could be matched over the two measurement points. Of the longitudinal sample, 56\% were male, $51 \%$ worked in the public sector, and $21 \%$ had a managerial position. In the first wave, participants in the longitudinal sample were on average 41.13 years of age ( $S D=9.01)$, worked 41.07 hours per week (including overtime, SD=7.98) and had been 13.56 years with their current employer $(\mathrm{SD}=10.49)$. 
In order to assess whether workers who participated in both surveys (Time 1, Time 2) shared demographic characteristics with those who only participated in the first round of data collection, t-tests and chi-square tests were conducted. The longitudinal sample was slightly older than the cross-sectional sample $\left(M_{\mathrm{L}}=41.12, M_{\mathrm{C}}=39.91, t(4299)=4.195, p<.001\right)$ and had worked longer for their employers $\left(M_{\mathrm{L}}=13.56, M_{\mathrm{C}}=12.31, t(4311)=3.955, p<.001\right)$. Moreover, the longitudinal sample included a larger percentage of workers in managerial positions $(21.2 \%$ versus $\left.17.8 \%, \chi^{2}(1)=8.176, \mathrm{p}<.01\right)$ and a larger percentage of public sector workers $(50.5 \%$ versus $\left.46.2 \%, \chi^{2}(1)=10.791, \mathrm{p}<.01\right)$, mainly because three private sector organizations did not participate in the second round of data collection. No differences were found with regard to gender and weekly working hours.

\subsection{Measures}

Demographic factors were assessed via single items. Respondents reported their gender (male=1, female=2), their age (in years), and their level of education (compulsory schooling=1, apprenticeship=2, 1-2 years vocational training=3, vocational school=4, 3-4 years vocational training $=5$, high school=6, university degree=7).

Structural work-related factors included respondents’ working hours (including overtime, in hours/week), frequency of ICT use ("How often do you use smartphones, tablet-pcs or PDAs for your work?” very seldom/never=1, once or several times a week=5), managerial position (no=0, yes=1), income (net salary per month $<1,000$ Euro=1, 1,001-1,500 Euro=2, 1,501-2,000 Euro=3, 2,001-2,500 Euro=4, 2,501-3,000 Euro=5, >3,001 Euro=6), and sector membership (private=1, public=2).

Personal resources, job resources, and IJDs were all assessed via mean-scales consisting of multiple items. Table 1 shows the references for these scales as well as the sample items. The range of the response options, descriptive statistics, and internal consistencies as indicated by Cronbach's Alpha (Time 1 and Time 2) are also presented in Table 1. All mean- 
scales showed an acceptable internal consistency at Time 1 and Time 2. Correlations between the variables studied are available from the first author upon request.

-Insert Table 1 about here

\subsection{Data analysis}

Research questions were examined by running hierarchical regression analyses (method enter) separately for five sub-dimensions of IJDs, serving as dependent variables one at the time. Specifically, we analyzed two types of regression models; the first models for crosssectional data (M1) and the second models for longitudinal data (M2). Both models included the following steps, except that in M2 the dependent variable at Time 1 (the predicted dimension of IJDs) was entered in the first step in order to control for the baseline level (stability) of the predicted variable. In the first step, we entered the demographic factors (gender, age, education), in the second step structural work-related factors (working hours, ICT use at work, managerial position, monthly income, sector), in the third step personal resources (personal initiative, optimism), and finally in the fourth step job resources (schedule control, task variety, supervisory support). Only complete datasets were used for the regression analyses. Therefore due to missing data the sample size for hypotheses testing was somewhat smaller $(\mathrm{N}=1,514-$ 1,522) than that for descriptive analyses $(\mathrm{N}=2,055)$.

\subsection{Results}

The results of the hierarchical regression analyses predicting five sub-dimensions of IJDs are presented for cross-sectional (M1) and longitudinal data (M2) in Table 2. Here we present predictors of the IJDs separately for each sub-dimension of IJDs. 
Work intensification (WI). Of the demographic factors, gender (being male) and younger age were associated with higher WI (in M2). Of the structural work-related factors, longer working hours (in M1), more frequent ICT use at work (in M1 and M2), having a managerial position (in M1) and employment in the public sector (in M2) explained significantly higher WI. Concerning personal resources, we found that employees with higher personal initiative (in M1 and M2) and with lower optimism (in M1) reported higher WI. All job resources were significant predictors of WI: lower schedule control (in M1 and M2) and higher task variety (in M1 and M2) were related to higher WI, as was lower supervisor support (in M1). Intensified job-related planning and decision-making demands (IJPD). Of the demographic factors, only lower level of education predicted higher IJPD (in M1). Four structural work factors were significant (in M1): longer working hours, more frequent ICT use, having a managerial position, and employment in the private sector predicted higher IJPD. Of the personal resources, having more personal initiative explained higher IJPD (in M1 and M2), whereas being optimistic was related to lower IJPD (in M1). Job resources were all significant antecedents: greater schedule control and greater task variety (in M1), and lower supervisor support (in M1 and M2) predicted higher IJPD.

Intensified career-related planning and decision-making demands (ICPD). Two demographic factors were significant: younger age (in M1 and M2) and higher level of education (in M1 and M2) were related to higher ICPD. Of the structural work factors, more frequent ICT use (in M1) and employment in the private sector (in M1 and M2) predicted higher ICPD. Both personal resources, i.e., higher personal initiative (in M1 and M2) and lower optimism (in M1) were associated with higher ICPD. Of the job resources, only lower supervisory support predicted higher ICPD (in M1).

Intensified knowledge-related learning demands (IKLD). Of the demographic factors, only gender (being male; in M1 and M2) and younger age (in M1) predicted higher IKLD. More frequent use of ICT, having a subordinate position, higher monthly income and 
working in the public sector were significant structural work factors associated with higher IKLD (in M1), whereas personal initiative was the only personal resource predicting higher IKLD (in M1). Concerning job resources, we found that lower schedule control (in M1) and higher task variety (in M1 and M2) were related to higher IKLD.

Intensified skill-related learning demands (ISLD). Gender (being male, in M1 and M2) younger age (in M1), and lower education (in M1) were associated with higher ISLD. Of the structural work factors, longer working hours and more frequent ICT use were significant predictors of ISLD (in M1). Those who were higher in personal initiative reported higher ISLD (in M1). Concerning job resources, lower schedule control (in M1), higher task variety (in M1 and M2), and lower supervisory support (in M1) were related to higher SLD.

The longitudinal regression analyses (M2) revealed that IJDs are fairly stable job demands, at least in a shorter time-span; the stability coefficients varied between .45 and .54 (Step 1) across the sub-dimensions of IJDs and the respective explanation rates varied between 24 and 36 percent. Thus employees who perceived higher (or lower) IJDs at one point in time were likely to have similar perceptions over time. It is also noteworthy that in the longitudinal models other predictors had very little explanatory power in explaining the variance of IJDs (0-2 \%) when the stability of each of the IJDs was analyzed.

\subsection{Conclusions}

\subsection{Discussion of study findings}

The present study examined various predictors of IJDs via cross-sectional and longitudinal designs. Due to a limited space we focus here on the most consistent predictors, i.e., those factors which predicted various dimensions of IJDs. The only fully consistent predictors, explaining all five dimensions of IJDs, were personal initiative and ICT use at work: those perceiving themselves to show high initiative at work and those reporting more frequent ICT use reported higher IJDs. This first finding was somewhat surprising as we considered personal 
initiative to be a positive personal resource that should counteract IJDs. Nevertheless, some earlier research has also shown that greater individual proactivity leads to increases in job demands over time (Li et al., 2014), implying that proactive people with high personal initiative may also experience more IJDs. These individuals very likely want to enhance their knowledge/expertise, learn new skills at work and be active in job- and career-related planning and decision-making. They may also prefer hard work and multitasking at work, implying more work intensification. These personal characteristics are surely beneficial for certain positive work-related outcomes, e.g., job performance (Fay and Frese, 2001; Frese et al., 1996, 1997). However, they may also constitute a risk factor for an individual, if (s)he has too much initiative (e.g., being involved in many work projects) or if the job demands become too intense/high (e.g., having too much cognitive load at work). This latter viewpoint is important as many organizations encourage their employees to show initiative and be independent decision-makers which, however, may imply more IJDs (see Dettmers et al., 2016; Kubicek et al., 2015, Paškvan and Kubicek, 2017).

The second finding, i.e., frequent ICT use at work predicted higher IJDs, is fully consistent with previous studies (Chesley, 2014) and also with the social acceleration theory, of which technological acceleration is a major hallmark (Rosa, 2003). In future, technological acceleration will even speed up due to digitalization, robotization, and artificial intelligence. These phenomena may confront employees with even more IJDs. This risk should be considered in organizations. Technological acceleration will have many implications in working life and not all of them are positive.

Higher task variety at work, lower supervisory support, younger age, and working in the public (WI, IKLD) or in the private sector (IJPD, ICPD) predicted higher IJDs as evaluated on four dimensions. Schedule control at work also explained four dimensions of IJDs, but the direction of this relationship was conditional upon the dimension of IJDs. Lower schedule control was related to higher WI and learning demands (IKLD, ISLD). However, 
higher schedule control predicted higher IJPD. Thus we found a scale-based variation concerning schedule control the effect of which depended on the dimension of IJDs.

As we used a longitudinal design and a time lag of more than one year, we were able to analyze the stability of IJDs. Our longitudinal regression analyses showed that IJDs were indeed somewhat stable over time; 24-36 percent of IJDs measured at Time 2 were explained by the Time 1 measurement (auto-regression coefficient). This means that an employee who experienced high IJDs at Time 1 was likely also to report high IJDs at Time 2. The stability of IJDs also reduced the predictive power of other antecedents in our longitudinal regression models. Despite high stability, some predictors, particularly personal initiative and job control (both schedule control and task variety) showed lagged, across-time effects on IJDs, signifying that these factors were robust longitudinal predictors of IJDs. It is noteworthy that stable IJDs may carry an elevated risk of chronic job stress, a hypothesis which needs to be confirmed in future longitudinal studies on IJDs as we did not focus here on the (stress, strain) outcomes of IJDs. Moreover, an examination of reversed or reciprocal causality (e.g., IJDs predict longer work hours or higher schedule control and not vice versa) may be another interesting avenue for future longitudinal studies.

\subsection{Practical implications}

Although ICT enables global interconnectedness and speeds up the coordination of work activities, these phenomena are associated with an intensification of job demands (Chesley, 2014). This paradoxical effect needs to be considered by organizational development practitioners and human resource managers when new technologies, e.g. in the form of digitalization, robotization, or artificial intelligence, are introduced into organizations. With the implementation of new technologies, secondary tasks, which need to be conducted in addition to core task, may indeed increase, causing IJDs. Practitioners should therefore consider the effects of new technologies on job demands and redesign work in accordance in order to decrease the health risks related to IJDs. 
Organizations wishing to counteract the intensification of job demands could focus on promoting supervisory support for employees as we found that lower supervisory support was associated with higher IJDs. On the one hand, support could be improved via personnel training. Training in goal setting or feedback techniques may help supervisors to set optimally challenging but achievable goals and to provide adequate feedback on job performance. Furthermore, knowledge and skills in work design help supervisors to adjust job demands so as still to provide challenges but not to overtax employees’ resources. On the other hand, in accordance with qualitative research (Hassard et al., 2011), our results suggest that supervisors may be particularly prone to experience work intensification. This may make it difficult for them to provide employees with adequate support. Therefore organizations need to provide their managers and supervisors with adequate resources to enable them to assist their employees if needed.

Setting challenging but achievable goals may also be important in light of our finding showing that individuals with high initiative were more likely to report higher IJDs (see also Dettmers et al., 2016). In order to protect employees against demanding too much of themselves in intensified working life, supervisors need to monitor employees’ job demands and intervene if these show major intensification. Involvement in multiple projects and teams, which are hallmarks of intensified, accelerated working life, carries a particular risk of overtaxing employees' resources. Therefore, goal setting should not focus on individual projects, but needs to take employees’ diverse work tasks into account to ensure that goals as a whole are achievable.

Finally, occupational health psychology has shown the crucial role of recovery from job demands for employees’ health and well-being (Sonnentag et al., 2017). Recovery, being able to switch-off and unwind during non-work time (free time, breaks), may be even more important in intensified working life, which is cognitively more demanding and packed with 
IJDs. Both organizations and individual employees should be aware of a need for recovery in such demanding work life settings.

\section{References}

Allvin, M., Aronsson, G., Hagström, T., Johansson, G. and Lundberg, U. (2011), Work without boundaries. Psychological Perspectives on the new working life, Wiley-Blackwell, Chichester, UK.

Anderson, G. (1996), “The benefits of optimism: A meta-analytic review of the life orientation test”, Personality and Individual Differences, Vol. 21 No. 2, pp. 719-725.

Bannai, A. and Tamakoshi, A. (2014), "The association between long working hours and health: A systematic review of epidemiological evidence”, Scandinavian Journal of Work, Environment and Health, Vol. 40 No. 1, pp. 5-18.

Bolger, N. and Zuckerman, A. (1995), "A framework for studying personality in the stress process”, Journal of Personality and Social Psychology, Vol. 69 No. 5, pp. 890-902.

Carstensen, L. (1991), “Selectivity theory: Social activity in life-span context”, Annual Review of Gerontology and Geriatrics, Vol. 11 No. 1, pp. 195-217.

Carver, C., Scheier, M. and Segerstrom, S. (2010), “Optimism”, Clinical Psychology Review, Vol. 30 No. 7, pp. 879-889.

Chesley, N. (2014), "Information and communication technology use, work intensification and employee strain and stress”, Work, Employment and Society, Vol. 28 No. 4, pp. 589-610.

Demerouti, E., Bakker, A., Nachreiner, F. and Schaufeli, W. (2001), “The job demandsresources model of burnout”, Journal of Applied Psychology, Vol. 86 No. 3, pp. 499-512.

Dettmers, J., Deci, N., Baeriswyl, S., Berset, M. and Krause, A. (2016), “Self-endangering work behavior”, in Wiencke, M., Fischer, S. and Cacace, M. (Eds.) Healthy at work -Interdisciplinary perspectives, Springer, Heidelberg, pp. 37-51.

Fay, D. and Frese, M. (2001), "The concept of personal initiative: An overview of validity studies”, Human Performance, Vol. 14 No. 1, pp. 97-124.

Felstead, A., Gallie, D., Green, F. and Inanc, H. (2013), Work Intensification in Britain: First Findings from the Skills and Employment Survey 2012, Centre for Learning and Life Chances in Knowledge Economies and Societies, Institute of Education, London, UK.

Franke, F. (2015), “Is work intensification extra stress?”, Journal of Personnel Psychology, Vol. 14 No. 1, pp. 17-27.

Frese, M. (1989), “Gütekriterien der Operationalisierung von sozialer Unterstützung am Arbeitsplatz”, Zeitschrift für Arbeitswissenschaft, Vol. 43, pp. 112-122.

Frese, M., Fay, D., Hilburger, T., Leng, K. and Tag, A. (1997), “The concept of personal initiative: Operationalization, reliability and validity in two German samples”, Journal of Occupational and Organizational Psychology, Vol. 70 No. 2, pp. 139-161.

Frese, M., Kring, W., Soose, A. and Zempel, J. (1996), "Personal initiative at work: Differences between East and West Germany”, Academy of Management Journal, Vol. 39 No. 1, pp. 37-63. 
Fisher, G., Infurna, F., Grosch, J., Stachowski, A., Faul, J. and Tetrick, L. (2014), "Mental work demands, retirement and longitudinal trajectories of cognitive functioning”, Journal of Occupational Health Psychology, Vol. 19 No. 2, pp. 231-242.

Furnham, A. (2008), Personality and intelligence at work: Exploring and explaining individual differences at work, Routledge, East Sussex, UK.

Gajendran, R. and Harrison, D. (2007), "The good, the bad, and the unknown about telecommuting: Meta-analysis of psychological mediators and individual consequences”, Journal of Applied Psychology, Vol. 92 No. 6, pp. 1524-1541.

Glaesmer, H., Hoyer, J., Klotsche, J. and Herzberg, P. (2008), "Die deutsche Version des LifeOrientation-Tests (LOT-R) zum dispositionellen Optimismus und Pessimismus" [The German version of the Life-Orientation-Test (LOT-R) for dispositional optimism and pessimism], Zeitschrift für Gesundheitspsychologie, Vol. 16 No. 1, pp. 26-31.

Gottschall, K., Kittel, B., Briken, K., Heuer, J.O., Hils, S., Streb, S. and Tepe, M. (2015), Public sector employment regimes: Transformations of the state as an employer, Palgrave Macmillan, Basingstoke, UK.

Grant, A.M. and Schwartz, B. (2011), "Too much of a good thing. The challenge and opportunity of the inverted u”, Perspectives of psychological science, Vol. 6 No. 1, pp. 61-76.

Green, F. (2004), "Work intensification, discretion, and the decline in well-being at work”, Eastern Economic Journal, Vol. 30 No. 4, pp. 615-625.

Gyllensten, K. and Palmer, S. (2005), “The role of gender in workplace stress: A critical literature review”, Health Education Journal, Vol. 64 No. 3, pp. 271-288.

Haus, M., Adler, C., Hagl, M., Maragkos, M. and Duschek, S. (2016), “Stress and stress management in European crisis managers”, International Journal of Emergency Services, Vol. 5 No. 1, pp. 66-81.

Hassard, J., McCann, L. and Morris, J. (2011), Managing in the modern corporation: The intensification of managerial work in the USA, UK and Japan, Cambridge University Press, Cambridge.

Humprey, S., Nahrgang, J. and Morgeson, F. (2007), “Integrating motivational, social and contextual work design features: A meta-analytic summary and theoretical extension of the work design literature”, Journal of Applied Psychology, Vol. 92 No. 5, pp. 1331-1356.

Häusser, J., Mojzisch, A., Niesel, M. and Schulz-Hardt, S. (2010), “Ten years: A review of recent research on the Job Demand-Control(-Support) model and psychological well-being”, Work and Stress, Vol. 24 No. 1, pp. 1-35.

Jick, T. and Mitz, L. (1985), “Sex differences in work stress”, The Academy of Management Review, Vol. 10 No. 3, pp. 408-420.

Karasek, R. (1979), "Job demands, job decision latitude and mental strain: Implications for job Redesign”, Administrative Science Quarterly, Vol. 24 No. 2, pp. 285-308.

Karasek, R. and Theorell, T. (1990), Healthy work: Stress, productivity and the reconstruction of working life, Basic Books, New York.

Korunka, C., Kubicek, B., Paskvan, M. and Ulferts, H. (2015), “Changes in work intensification and intensified learning: Challenge or hindrance demands?”, Journal of Managerial Psychology, Vol. 30 No. 7, pp. 786-800. 
Kubicek, B., Paškvan, M. and Korunka, C. (2015), “Development and validation of an instrument for assessing job demands arising from accelerated change: The intensification of job demands scale (IDS)”, European Journal of Work and Organizational Psychology, Vol. 24 No. 6, pp. 898-913.

Kubicek, B., Korunka, C., Paškvan, M., Prem, R. and Gerdenitsch, C. (2014), “Changing working conditions at the onset of the twenty-first century: Facts from international datasets”, in: Korunka, C. and Hoonakker, P. (Eds.), The Impact of ICT on Quality of Working Life, Springer, Dordrecht, pp. 25-41.

Lee, K., Suh, C., Kim, J.E. and Parks, J.O. (2017), “The impact of long working hours on psychological stress response among white-collar workers”, Industrial Health, Vol. 55 No. 1, pp. 46-53.

Li, W.D., Fay, D., Frese, M., Harms, P. and Gao, X. (2014), “Reciprocal relationship between proactive personality and work characteristics: A latent change score approach”, Journal of Applied Psychology, Vol. 99 No. 5, pp. 948-958.

Martin, M. and Zimprich, D. (2005), “Cognitive development in midlife”, in Willis, S. and Martin, M. (Eds.), Middle Adulthood. A lifespan perspective, Sage Publications, Thousand Oaks, pp. 179-204.

Munnell, A. and Fraenkel, R. (2013), "Public sector workers and job security, State and Local Pension Plans, Vol. 31, Chestnut Hill, Mass.: Center for Retirement Research at Boston College, available at: http://dlib.bc.edu/islandora/object/bc-ir:103848 (accessed 22 March 2018).

Major, D., Turner, J. and Fletcher, T. (2006), "Linking proactive personality and the Big Five to motivation to learn and development activity”, Journal of Applied Psychology, Vol. 91 No. 4, pp. 927-935.

Omari, M. and Paull, M. (2015), "Public sector work intensification and negative behaviors", Journal of Organizational Change Management, Vol. 28 No. 4, pp. 603-613.

Paškvan, M. and Kubicek, B. (2017), “The intensification of work”, in C. Korunka \& B. Kubicek (Eds.), Job demands in a changing world of work, Springer, Cham, UK, pp. 25-43.

Pinquart, M. and Sorensen, S. (2000), "The influences of socioeconomic status, social networks, and competence on subjective well-being in later life: A meta-analysis”, Psychology and Aging Vol. 15 No. 2, pp. 187-224.

Pongratz, H. and Voß, G. (2003), "From employee to 'entreployee': Towards a 'selfentrepreneurial’ work force?” Concepts and Transformation, Vol. 8 No. 3, pp. 239-254.

Rosa, H. (2003), "Social acceleration: Ethical and political consequences of a desynchronized high-speed society”, Constellations, Vol. 10 No. 1, pp. 3-33.

Scheier, M. and Carver, C. (1992), "Effects of optimism on psychological and physical wellbeing: Theoretical overview and empirical update”, Cognitive Therapy Research, Vol. 16 No. 2, pp. 201-228.

Semmer, N., Zapf, D. and Dunckel, H. (Eds.) (1998), “Instrument zur streßbezogenen

Tätigkeitsanalyse ISTA [Instrument for stressrelated job analysis ISTA]“, Verlag der Fachvereine Hochschulverlag, Zürich.

Sonnentag, S., Venz, L. and Casper, A. (2017), “Advances in recovery research: What we have learned? What should be done next?“, Journal of Occupational Health Psychology, Vol. 22 No. 3, pp 365-380. 
Stegmann, S., van Dick, R., Ullrich, J., Charalambous, J., Menzel, B., Egold, N. and Wu, T. (2010), "Der Work Design Questionnaire. Vorstellung und erste Validierung einer deutschen Version [The work design questionnaire. Conception and validation of a German version]“, Zeitschrift für Arbeits- und Organisationspsychologie, Vol. 54 No. 1, pp. 1-28.

Van der Heijden, B. and De Vos, A. (2015), "Sustainable careers: Introductory chapter”, in De Vos, A. \& Van der Heijden, B.I.J.M. (Eds.), Handbook of research on sustainable careers Edward Elgar, Cheltenham, UK, pp. 1-19.

van der Doef, M. and Maes, S. (1999), “The job Demand-Control(-Support) model and psychological well-being: A review of 20 years of empirical research”, Work \& Stress, Vol. 13 No. 2, pp. 87-114.

Wood, L. (2011), “The changing nature of jobs: A meta-analysis examining changes in job characteristics over time" (Master thesis), University of Georgia, Athens, GA, available at: http://dbs.galib. uga.edu/cgi-bin/getd.cgi?userid=galileo\&serverno=8\&instcode= publ\&_cc=1 (accessed 22 March 2018).

Warren, J., Hoonakker, P., Carayon, P. and Brand, J. (2004), "Job characteristics as mediators in SES-health relationships”, Social Science \& Medicine, Vol. 59 No. 7, pp. 1367-1378.

Waszkowska , M., Jacukowicz, A., Drabek, M. and Merecz-Kot, D. (2017), “Effort-reward balance as a mediator between supplementary person-organization fit and perceived stress among middle-level managers”, International Journal of Occupational Medicine and Environmental Health, Vol. 30 No. 2, pp. 305-331. 
Table 1. A summary table on measures (sum-scales based on multiple items)

\begin{tabular}{|c|c|c|c|c|c|c|c|c|c|c|}
\hline \multirow[t]{2}{*}{ Construct } & \multirow[t]{2}{*}{ Scale } & \multirow[t]{2}{*}{ Sample items/questions } & \multirow[t]{2}{*}{$\begin{array}{l}\text { Number } \\
\text { of items }\end{array}$} & \multirow[t]{2}{*}{ Range } & \multicolumn{3}{|c|}{$\begin{array}{l}\text { Cross-sectional } \\
\text { sample }\end{array}$} & \multicolumn{3}{|c|}{$\begin{array}{l}\text { Longitudinal } \\
\text { sample }\end{array}$} \\
\hline & & & & & $\alpha$ & $M$ & $S D$ & $\alpha$ & $M$ & $S D$ \\
\hline Optimism & $\begin{array}{l}\text { Life-Orientation Test (LOT- } \\
\text { R, German version: } \\
\text { Glaesmer et al., 2008) }\end{array}$ & $\begin{array}{l}\text { In uncertain times, I usually } \\
\text { expect the best. }\end{array}$ & 3 & $1-5$ & .77 & 3.77 & 0.76 & .77 & 3.79 & 0.74 \\
\hline $\begin{array}{l}\text { Job control: Schedule } \\
\text { control }\end{array}$ & $\begin{array}{l}\text { Instrument for stress-related } \\
\text { job analysis (ISTA, Semmer } \\
\text { et al., 1998) }\end{array}$ & $\begin{array}{l}\text { To what extent are you able to } \\
\text { plan your working day } \\
\text { yourself? }\end{array}$ & 3 & $1-5$ & .81 & 3.42 & 0.94 & .81 & 3.50 & 0.89 \\
\hline Job control: Task variety & $\begin{array}{l}\text { Work Design Questionnaire } \\
\text { (WDQ, German version: } \\
\text { Stegmann et al., 2010) }\end{array}$ & $\begin{array}{l}\text { The job involves performing a } \\
\text { variety of tasks. }\end{array}$ & 4 & $1-6$ & .88 & 4.45 & 0.98 & .87 & 4.55 & 0.93 \\
\hline $\begin{array}{l}\text { Work intensification } \\
\text { (WI) }\end{array}$ & \multirow[t]{3}{*}{$\begin{array}{l}\text { Intensification of job } \\
\text { demands scale (IJDs, } \\
\text { Kubicek et al., 2015) }\end{array}$} & $\begin{array}{l}\text { In the last five years, it is } \\
\text { increasingly rare to have } \\
\text { enough time for work tasks. }\end{array}$ & 5 & $1-5$ & .88 & 3.34 & 0.99 & .89 & 3.32 & 1.00 \\
\hline $\begin{array}{l}\text { Intensified job-related } \\
\text { planning demands } \\
\text { (IJPD) }\end{array}$ & & $\begin{array}{l}\text {... more often decisions have } \\
\text { to be made without } \\
\text { consultation with supervisors. }\end{array}$ & 5 & $1-5$ & .85 & 3.27 & 0.95 & .87 & 3.26 & 0.97 \\
\hline $\begin{array}{l}\text { Intensified career- } \\
\text { related planning } \\
\text { demands (ICPD) }\end{array}$ & & $\begin{array}{l}\ldots \text { one increasingly has to } \\
\text { plan one's professional career } \\
\text { independently. }\end{array}$ & 3 & $1-5$ & .78 & 3.22 & 1.05 & .79 & 3.13 & 1.06 \\
\hline
\end{tabular}




\begin{tabular}{|c|c|c|c|c|c|c|c|c|c|}
\hline $\begin{array}{l}\text { Intensified knowledge- } \\
\text { related learning } \\
\text { demands (IKLD) }\end{array}$ & $\begin{array}{l}\text {... one increasingly has to } \\
\text { acquire new knowledge to } \\
\text { handle job tasks. }\end{array}$ & 3 & $1-5$ & .86 & 3.57 & 0.91 & .86 & 3.59 & 0.89 \\
\hline $\begin{array}{l}\text { Intensified skill-related } \\
\text { learning demands } \\
\text { (ISLD) }\end{array}$ & $\begin{array}{l}\text {... one increasingly has to get } \\
\text { used to new workflows. }\end{array}$ & 3 & $1-5$ & .83 & 3.29 & 0.91 & .83 & 3.31 & 0.88 \\
\hline
\end{tabular}


Table 2. Predicting IJDs in cross-sectional (Model 1, M1, n = 3336-3344)) and longitudinal (Model 2, M2, $\mathrm{n}=1514-1522$ ) data. Standardized beta-coefficients from the final step (Step 4 in M1; Step 5 in $M 2$ ), $\Delta \mathrm{R}^{2}$, and adjusted $\mathrm{R}^{2}$

\begin{tabular}{|c|c|c|c|c|c|c|c|c|c|c|}
\hline \multirow{2}{*}{$\begin{array}{l}\text { Predictor variable } \\
\text { M1, M2 }\end{array}$} & \multicolumn{2}{|l|}{ WI } & \multicolumn{2}{|l|}{ IJPD } & \multicolumn{2}{|l|}{ ICPD } & \multicolumn{2}{|l|}{ IKLD } & \multicolumn{2}{|l|}{ ISLD } \\
\hline & M1 & M2 & M1 & M2 & M1 & M2 & M1 & M2 & M1 & M2 \\
\hline Dependent variable at T1 (M2) & - & $.54 * * *$ & - & $.49 * * *$ & - & $.49 * * *$ & - & $.46^{* * *}$ & - & $.45 * * *$ \\
\hline$\Delta \mathrm{R}^{2}$ & - & $.36 * * *$ & - & $.31 * * *$ & - & $.31^{* * *}$ & - & $.26 * * *$ & - & $.24 * * *$ \\
\hline \multicolumn{11}{|l|}{ Demographical factors } \\
\hline Gender (male/female) & .03 & $-.05 *$ & -.02 & -.03 & -.004 & -.02 & $-.08 * * *$ & $-.11 * * *$ & $-.04 *$ & $-.09 * * *$ \\
\hline Age (low/high) & .02 & $-.05^{*}$ & .01 & -.01 & $-.12 * * *$ & $-.06^{*}$ & $-.04^{*}$ & -.04 & $-.04 *$ & -.01 \\
\hline Education (low/high) & .01 & .01 & $-.07 * * *$ & -.05 & $.04 *$ & $.05^{*}$ & -.03 & -.01 & $-.06 * * *$ & -.02 \\
\hline$\Delta \mathrm{R}^{2}$ & $.01 * * *$ & $.01 * * *$ & $.02 * * *$ & .00 & $.03 * * *$ & $.01 * * *$ & $.02 * * *$ & $.02 * * *$ & $.01^{* * *}$ & $.01^{* * *}$ \\
\hline \multicolumn{11}{|l|}{ Structural work factors } \\
\hline Working hours (low/high) & $.09 * * *$ & -.01 & $.07 * * *$ & -.02 & .01 & .03 & .03 & -.03 & $.05^{*}$ & -.03 \\
\hline ICT use at work (low/high) & $.12 * * *$ & $.06^{*}$ & $.12 * * *$ & .01 & $.10^{* * *}$ & .03 & $.09 * * *$ & .03 & $.04 *$ & .01 \\
\hline Managerial position (no/yes) & $.04^{*}$ & -.02 & $.04 *$ & .05 & -.01 & -.004 & $-.05 * *$ & -.002 & .01 & .01 \\
\hline Incomes in month (low/high) & .01 & .06 & .01 & .05 & .02 & .00 & $.09 * * *$ & .05 & .03 & .04 \\
\hline Sector (private/public) & .02 & $.08 * * *$ & $-.11^{* * *}$ & -.01 & $-.15^{* * *}$ & $-.07 * *$ & $.07 * * *$ & .02 & .02 & -.02 \\
\hline$\Delta \mathrm{R}^{2}$ & $.05 * * *$ & $.01^{* * *}$ & $.12 * * *$ & $.01^{* *}$ & $.06 * * *$ & $.01^{* * *}$ & $.05^{* * *}$ & .00 & $.03 * * *$ & .00 \\
\hline \multicolumn{11}{|l|}{ Personal resources } \\
\hline Personal initiative & $.16^{* * * *}$ & $.05^{*}$ & $.20 * * *$ & $.06^{*}$ & $.25 * * *$ & $.09 * * *$ & $.14^{* * *}$ & .04 & $.14 * * *$ & .04 \\
\hline Optimism & $-.09 * * *$ & .00 & $-.04 *$ & -.02 & $-.06 * *$ & .00 & -.013 & -.03 & -.01 & -.004 \\
\hline
\end{tabular}




\begin{tabular}{|c|c|c|c|c|c|c|c|c|c|c|}
\hline$\Delta \mathrm{R}^{2}$ & $.04 * * *$ & $.003 *$ & $.05 * * *$ & $.003 *$ & $.05 * * *$ & $.01 * *$ & $.03 * * *$ & .00 & $.03 * * *$ & .00 \\
\hline \multicolumn{11}{|l|}{ Job resources } \\
\hline Schedule control & $-.26 * * *$ & $-.08 * * *$ & $.12^{* * *}$ & .04 & .01 & .04 & $-.12 * * *$ & -.01 & $-.12 * * *$ & -.04 \\
\hline Task variety & $.17 * * *$ & $.06^{* *}$ & $.17 * * *$ & .02 & .01 & -.004 & $.21 * * *$ & $.08 * *$ & $.18 * * *$ & $.06^{*}$ \\
\hline Supervisory support & $-.18 * * *$ & -.01 & $-.12 * * *$ & $-.05 *$ & $-.18 * * *$ & -.04 & -.02 & -.05 & $-.04 *$ & -.03 \\
\hline$\Delta \mathrm{R}^{2}$ & $.11 * * *$ & $.01 * *$ & $.04 * * *$ & .00 & $.03 * * *$ & .00 & $.04 * * *$ & $.01 * *$ & $.03 * * *$ & $.004 *$ \\
\hline Adjusted $\mathrm{R}^{2}$ & $.21 * * * *$ & $.38 * * *$ & $.23 * * *$ & $.32 * * *$ & $.16 * * *$ & $.33 * * *$ & $.13 * * *$ & $.28 * * *$ & $.09 * * *$ & $.25 * * *$ \\
\hline
\end{tabular}

${ }^{*} \mathrm{p}<.05, * * \mathrm{p}<.01, * * * \mathrm{p}<.001$

Note. WI=Work intensification; IJPD=Intensified job-related planning and decision-making demands; ICPD=Intensified career-related planning and decisionmaking demands; IKLD=Intensified knowledge-related learning demands; ISLD=Intensified skill-related learning demands. 